\title{
Ubiquitous neurocognitive dysfunction in familial adenomatous polyposis: proof-of- concept of the role of APC protein in neurocognitive function
}

\author{
Marcia Roxana Cruz-Correa ${ }^{1,2,4,5^{*}}$ (D), Ana Cecilia Sala ${ }^{1}$, Beatriz Cintrón ${ }^{1}$, Jessica Hernández ${ }^{1}$, Myrta Olivera ${ }^{1}$, \\ Adrian Cora ${ }^{1}$, Constance M. Moore ${ }^{6}$, Carlos A. Luciano ${ }^{3}$, Marievelisse Soto-Salgado ${ }^{1}$, Francis M. Giardiello ${ }^{5}$ and \\ Stephen R. Hooper ${ }^{7}$
}

\begin{abstract}
Background: Familial adenomatous polyposis (FAP) is an autosomal dominant disorder caused by germline mutations in the APC gene. Patients with FAP have multiple extraintestinal manifestations that follow a genotypephenotype pattern; however, few data exist characterizing their cognitive abilities. Given the role of the APC protein in development of the central nervous system, we hypothesized that patients with FAP would show differences in cognitive functioning compared to controls.

Methods: Matched case-control study designed to evaluate cognitive function using the Test of Nonverbal Intelligence-4, the Bateria III Woodcock-Munoz, and the Behavior Rating Inventory of Executive Functions-Adult. Twenty-six individuals with FAP (mean age $=34.2 \pm 15.0$ years) and 25 age-gender and educational level matched controls (mean age $=32.7 \pm 13.8$ years) were evaluated.

Results: FAP-cases had significantly lower IQ $(p=0.005)$. Across all tasks of the Batería III Woodcock-Muñoz, FAPcases performed significantly lower than controls, with all of the summary scores falling in the bottom quartile compared to controls $(p<0.0001)$. Patients with FAP scored within the deficient range for Long-Term Retrieval and Cognitive Fluency.

Conclusion: APC protein has an important role in neurocognitive function. The pervasive nature of the observed cognitive dysfunction suggests that loss or dysfunction of the APC protein impacts processes in cortical and subcortical brain regions. Additional studies examining larger ethnically diverse cohorts with FAP are warranted.
\end{abstract}

Keywords: Familial adenomatous polyposis, Neurocognition, Hispanics, FAP

\section{Introduction}

Familial adenomatous polyposis (FAP) is an autosomal dominant disorder caused by germline mutations in the Adenomatous Polyposis Coli (APC). There are multiple extraintestinal manifestations that follow a genotypephenotype pattern [1]; however, few data characterize the

\footnotetext{
* Correspondence: marcia.cruz1@upr.edu

'Department of Medicine, University of Puerto Rico School of Medicine, UPR Medical Sciences Campus, PO BOX 365067, San Juan 00936, Puerto Rico

${ }^{2}$ Department of Biochemistry, University of Puerto Rico School of Medicine,

San Juan, Puerto Rico

Full list of author information is available at the end of the article
}

cognitive abilities of individuals with FAP. The APC protein has a major function in the development of the central nervous system, including a pivotal role in the development of the pre-post synaptic complex seen in invivo [2] and animal studies [3]. Moreover, high concentrations of the APC protein are present in the hippocampus, thalamus, and limbic system. Consequently, specific difficulties in the neurocognitive domains of attention, memory, and executive functions among individuals with deficient APC protein function might be expected.

Despite these known linkages few empirical findings examining the relationship between the expression of 
the APC protein and neurocognitive and behavioral functioning in individuals with APC mutations exist [47]. To date, animal studies have associated APC dysfunction with altered synaptic function in APC $\mathrm{cKO}$ mice, which plays a critical role in learning and memory [8]. The genetic changes in APC that have been implicated in learning and memory deficits, repetitive behaviors, and reduced social interest [8], also have been associated with working memory deficits, increased locomotion, and anxiety-related behavior [3]. Though frequently hypothesized that genetic factors play an important role in psychiatric disorders, identification of specific genes has been a difficult task. Interestingly, preliminary findings implicate the APC gene in psychiatric disorders such as schizophrenia $[9,10]$ and depression [11]. These psychiatric conditions have also been related to cognitive and behavioral impairments.

The primary aims of this exploratory study were to determine: (1) whether patients with FAP would evidence differences in performance on measures of neurocognitive function compared with non-affected controls; and (2) if neurocognitive manifestations followed a genotypephenotype distribution as seen with other clinical manifestations in FAP. Given the major role of the APC protein in the development of the central nervous system, including the development of the pre-post synaptic complex seen in in vitro $[2,12]$ and in vivo [8] studies, we hypothesized that individuals with FAP would show lower cognitive functioning compared to non-FAP controls across all ages. Given the potential for synaptic dysfunction, we would expect tasks related to processing speed and cognitive efficiency to be the most affected.

\section{Methods}

\section{Participants}

Sample size calculations were based on data from O'Malley et al. [13] who reported a lower Verbal IQ for individuals with FAP compared to historical average scores. Using the Batería III Woodcock-Muñoz, with a mean IQ $=100(\mathrm{SD}=15)$ a sample size of 23 in each group will have $90 \%$ power to detect a probability of 0.240 (effect size) that an observation in Group 1 is less than an observation in Group 2 using a Wilcoxon (Mann-Whitney) rank-sum test with a 0.050 two-sided significance level. Participants for both groups (ages $\geq 10$ years) were ascertained via the Puerto Rico Familial Colorectal Cancer Registry (http://purificar.rcm.upr.edu/ index_eng.html).

Inclusion criteria for cases included genetically confirmed FAP (based on a mutation on the APC gene performed by commercial laboratory testing), age $\geq 10$ years, able to assent (children) and consent (adults) to participate in this study, and able to complete all neurocognitive testing. Inclusion criteria for controls included no known family history of FAP, negative clinical diagnosis of FAP based on colonoscopy (for adults), and willingness to undergo neurocognitive testing. Participants were all Spanish-speaking individuals from Puerto Rico. As education and age are correlated with IQ, cases were matched to non-FAP control individuals with regards to age ( \pm three years), gender, and education (less than high school, at least high school, bachelors-degree or postgraduate education). Exclusion criteria for both cases and controls included previous diagnosis of any major psychiatric condition given the potential impact of these conditions on neurocognitive functioning, inability to sign/assent/consent study participation, or complete the neurocognitive tests.

Participants signed informed consent (or assent for children) prior to participation in the study and were evaluated at the Puerto Rico Clinical and Translational Research Consortium at the University of Puerto Rico (UPR) Medical Sciences Campus. The research protocol was approved by the Institutional Review Board of the UPR Medical Sciences Campus.

\section{Measures and procedures}

Neurocognitive procedures were carried out by licensed psychologists with extensive expertise in evaluation of neurocognitive disorders in children with genetic conditions. Selection of measures for this study was based on the following criteria: (1) tests have hypothesized links to brain regions where there are known high concentrations of APC protein; (2) age-appropriateness, with tasks going across the lifespan; (3) well established standardization and age-based normative data; and (4) strong psychometric properties. These outcome measures included the Test of Nonverbal Intelligence-4, the Batería III Woodcock-Mũnoz, and the Behavior Rating Inventory of Executive Functions-Adult. Measures of anxiety (General Anxiety Disorder Questionnaire-7), social communication (Social Communication Questionnaire), and depression (Patient Health Questionnaire-9) were used as potential covariates.

Batería III Woodcock-Mũnoz We used the cognitive components of this battery, which was translated and adapted from the publisher of the Woodcock-Johnson III Cognitive Battery via a calibration sample of approximately 1400 individuals from both the United States and several Spanish speaking countries including Puerto Rico. This battery is based on the Cattell-Horn-Carroll model of cognitive abilities and includes measures of comprehensionknowledge, visual-spatial thinking, auditory processing, processing speed, short-term memory, long-term memory, working memory, broad attention, and executive processes. This measure retains a high degree of technical adequacy with reliability for all of the clusters being $\geq 0.90$ across all of the age ranges. 
Test of nonverbal intelligence (TONI-4) Although the Batería III Woodcock-Mũnoz can generate a General Intellectual Factor, its use as a covariate in any of our analyses will confound group findings from the cognitive clusters as the intellectual estimate contains many of the same subtests. In that regard, for our overall measure of intellectual functioning, we have included a nonverbal measure of intellectual functioning: the TONI-4. While hoping to utilize the KBIT-2 to replicate the findings of O'Malley et al. [13] there is no Spanish version of this test; consequently, using the TONI- 4 provides a broader application for our sample and serves as a subject descriptive variable and as a potential covariate in the data analyses. The TONI-4 measures the ability to solve problems without overtly using language or complex motor responses, requiring the person to apply reasoning strategies to a problem defined by novel abstract figures. It includes verbal directions in Spanish, and responses require only simple pointing or gestures. The psychometric properties and normative basis of the TONI-4 are strong.

Behavior rating inventory of executive functions (BRIEF)-parent and adult versions The BRIEF is a behavior rating scale of executive functions in everyday life that is completed by the parent (up to age 18 years) or an individual (ages 18 and older). The BRIEF provides ecological measures of a variety of executive functions that address regulatory activities in day-to-day functioning. It comprises specific clinical scales (e.g., Organization, Shift, Working Memory, etc.) and three summary scales: Behavioral Regulation Index, Metacognition Index, and Global Executive Composite. Each version of the scale is standardized, well normed, has strong psychometric properties, and is available in both English and Spanish.

Patient health questionnaire (PHQ9) The PHQ9 is a nine-item depression scale completed by the individual. It is a multiple-choice self-report inventory used as a screening and diagnostic tool for depression, anxiety, alcohol, eating, and somatoform conditions.

Generalized anxiety disorder (GAD-7) The GAD-7 is a self-reported questionnaire for screening and severity of generalized anxiety disorder. The GAD-7 has seven items, which measure severity of various signs of generalized anxiety disorder according to reported response categories with assigned points.

\section{Neurological exam}

All patients underwent a full neurologic examination exam performed by a neurologist that included a screening for mental status, apraxia, agnosia, aphasia, cranial nerve status, motor and sensory intactness, motor coordination, and deep tendon and corticospinal tract reflexes.

\section{Data analyses}

Preliminary data analyses included a comparison of selected sociodemographic characteristics by study group (FAP vs. Control) using $X^{2}$ test or Fisher's exact test. The anxiety and depression scores were compared by study group (FAP vs. Control) using t-tests or Wilcoxon ranksum test. To address group differences in neurocognition, simple and multiple linear regression models were used to estimate the unadjusted and adjusted beta (B) coefficients with their $95 \%$ confidence intervals. The models were adjusted by age, gender, and educational level. $P$-values were corrected using the BonferroniHolm method (https://www.statisticshowto.datasciencecentral.com/holm-bonferroni-method/). To establish significance, observed $p$-values were compared with corrected $p$-values. If (1) observed $p$-values were lower than corrected $p$-values, and (2) there was an intersection between the significant $p$-values across the tests for each measure, then, neurocognitive measure was established to be significant.

For the evaluation of neurocognitive function status across the APC gene mutation spectrum, FAP patients were stratified according to location of mutations in the gene. Specifically, genotype-phenotype analysis was performed comparing individuals with mutations in codons within the attenuated-FAP region (codons $<1000$ and $>$ $1500 ; N=9$ ) and those within the mutation cluster region (between codons 1000 to 1500; $N=17$ ). To determine the effect of the FAP genotype-phenotype, we used simple linear regression models and adjusted linear regression models with $95 \%$ confidence intervals. The models were adjusted by age, gender, and educational attainment. Statistical analyses were performed using Stata 14.0.

\section{Results \\ Baseline demographic and clinical characteristics}

Baseline demographic characteristics are presented in Table 1. Study participants (cases and controls) were equivalent with regards to age (mean age $34.2 \pm 15.0$ vs. $32.7 \pm 13.8, p=0.59)$, gender $(p=0.68)$, and educational level $(p=0.10)$, with both groups being unremarkable in the reporting of their symptoms. There were no statistically significant differences between patients with FAP and controls with regard to baseline anxiety $(p=0.21)$ and depression $(p=0.09)$ (data not shown).

\section{Intelligence}

Group differences on the TONI-4, our measure of Intelligence, are presented in Table 2. Both FAP cases and controls fell within the average range of functioning, although the FAP patients had statistically significantly 
Table 1 Baseline demographic characteristics of study participants

\begin{tabular}{|c|c|c|c|}
\hline Characteristic & FAP group $(n=26)$ & Control group $(n=25)$ & $p$-value ${ }^{*}$ \\
\hline Age & & & 0.59 \\
\hline$<21$ years & $8(30.8)$ & $6(24.0)$ & \\
\hline$\geq 21$ years & $18(69.2)$ & $19(76.0)$ & \\
\hline Mean \pm SD & $34.2 \pm 15.0$ & $32.7 \pm 13.8$ & \\
\hline Gender & & & 0.68 \\
\hline Male & $14(53.9)$ & $12(48.0)$ & \\
\hline Female & $12(46.2)$ & $13(52.0)$ & \\
\hline Medical insurance & & & 0.28 \\
\hline None & $1(4.2)$ & $2(8.3)$ & \\
\hline Private & $13(54.1)$ & $17(70.8)$ & \\
\hline Public & $10(41.7)$ & $5(20.8)$ & \\
\hline Educational level & & & 0.09 \\
\hline$<12$ & $4(15.4)$ & $9(36.0)$ & \\
\hline$\geq 12$ & $22(84.6)$ & $16(64.0)$ & \\
\hline Grade repetitions & & & 0.45 \\
\hline No & $15(57.7)$ & $17(68.0)$ & \\
\hline Yes & $11(42.3)$ & $8(32.0)$ & \\
\hline
\end{tabular}

${ }^{*} p$-value from the $x^{2}$ test or Fisher's exact test

lower functioning compared with age-, gender- and education-matched controls $(90.5 \pm 5.6$ vs. $95.6 \pm 6.8$, $p=0.008)$.

\section{Neurocognitive functioning}

Batería-III summary scores Findings of the groups on the Batería-III summary scores are shown in Table 2. Across all of the Batería-III summary scores, FAP cases reflected significantly more risk for cognitive dysfunction than the controls, with the cases showing performances in the lower quartile on Verbal Ability, Thinking Ability, Cognitive Efficiency, Long-Term Retrieval, Processing Speed, Phonemic Awareness, Working Memory, Cognitive Fluency, and Executive Processes. In particular, FAP cases scored within the deficient range for Long-Term Retrieval and Cognitive Fluency.

Specific group comparisons on the obtained scores revealed a similar pattern of findings wherein the FAP Group performed significantly lower than controls on: Verbal Ability (LRM - 7.2, $p=0.002$ ); Thinking Ability (LRM - 16.9, $p<0.0001$; Cognitive Efficiency (LRM - 13.3, $\mathrm{p}<0.0001$ ); Long-Term Memory (LRM - 18.3, p < 0.0001); Processing Speed (LRM - 17.2, p $<0.0001$; Phonemic Awareness (LRM - 8.5, $p=0.004$ ); Working Memory (LRM - 11.2, $p=0.001)$; Cognitive Fluency (LRM - 14.8, $\mathrm{p}<0.0001)$; and Executive Processes (LRM - 17.1, $\mathrm{p}<0.0001)$.

Batería-III subtests An exploratory examination of group differences on the Batería-III subtests was conducted to determine if any of the subtests were influential in the summary score findings. Specifically, 13 of the 15 subtests produced significant group differences, with FAP cases performing below controls on each of these 13 subtests. Effect sizes were in the large range in every instance. After Bonferonni Correction (i.e., $p<0.003$ ), nine of the Batería-III subtests remained statistically significant including: Verbal Comprehension, Visual-Auditory Learning, Spatial Relations, Sound Blending, Concept Formation, Visual Matching, Auditory Working Memory, Retrieval Fluency, and Decision Speed.

\section{Group differences in ratings of executive functions}

We only had five cases where parents and child needed to complete the BRIEF, and all fell within the average range. Consequently, given the small sample size, no further analysis was conducted (data not shown). For the Adult BRIEF, both cases and controls rated their executive functioning to be within the average range. Group comparisons (FAP cases vs. controls) did not show any significant differences on any of the individual or summary scales of the BRIEF-Adult (Table 2).

\section{Genotype-phenotype correlation analysis}

Neurocognitive status was analyzed according to APC mutation location (Table 3). FAP cases were grouped in two categories based on APC gene mutations: attenuated FAP (mutations in codons $<1000$ and $>1500 ; N=9$ ) and classic FAP, those with an APC gene mutation in the mutation cluster region (between codons 1000 to 1500; 
Table 2 Comparison of the FAP and control groups on the neurocognitive functions

\begin{tabular}{|c|c|c|c|c|c|c|c|c|c|c|c|}
\hline \multirow[t]{2}{*}{ Measure } & \multicolumn{2}{|c|}{$\begin{array}{l}\text { FAP group } \\
(\mathrm{n}=26)\end{array}$} & \multicolumn{2}{|c|}{$\begin{array}{l}\text { Control group }(n= \\
25)\end{array}$} & \multirow[t]{2}{*}{$p$-value ${ }^{*}$} & \multirow[t]{2}{*}{$\begin{array}{l}\text { Simple LRM } \\
\text { (coefficients) }\end{array}$} & \multirow[t]{2}{*}{$p$-value } & \multirow{2}{*}{$\begin{array}{l}\text { Adjusted } \\
\text { multivariate } \\
\text { LRM** } \\
\text { (coefficients) }\end{array}$} & \multirow[t]{2}{*}{$p$-value } & \multirow{2}{*}{$\begin{array}{l}\text { Adjusted } \\
\text { multivariate } \\
\text { LRM*** } \\
\text { (coefficients) }\end{array}$} & \multirow[t]{2}{*}{$p$-value } \\
\hline & Mean & $\mathrm{SD}$ & Mean & SD & & & & & & & \\
\hline$\overline{T O N I-4 ~ I Q ~}$ & 90.5 & 5.6 & 95.6 & 6.8 & 0.005 & -5.1 & 0.005 & -5.2 & 0.005 & -5.0 & 0.008 \\
\hline \multicolumn{12}{|l|}{ Batería III clusters } \\
\hline Verbal ability ${ }^{\#}$ & 88.2 & 7.7 & 95.7 & 7.8 & 0.001 & -7.5 & 0.001 & -7.4 & 0.001 & -7.2 & 0.002 \\
\hline Thinking ability ${ }^{\#}$ & 80.5 & 10.5 & 97.8 & 10.3 & $<0.0001$ & -17.3 & $<0.0001$ & -16.7 & $<0.0001$ & -16.9 & $<0.0001$ \\
\hline Cognitive efficiency ${ }^{\#}$ & 81.1 & 11.9 & 94.7 & 9.9 & 0.0001 & -13.6 & $<0.0001$ & -13.4 & $<0.0001$ & -13.3 & $<0.0001$ \\
\hline Long-term memory $^{\#}$ & 66.8 & 14.3 & 85.1 & 12.1 & $<0.0001$ & -18.3 & $<0.0001$ & -17.8 & $<0.0001$ & -18.3 & $<0.0001$ \\
\hline Processing speed ${ }^{\#}$ & 85.1 & 14.7 & 102.0 & 9.7 & $<0.0001$ & -16.9 & $<0.0001$ & -16.6 & $<0.0001$ & -17.2 & $<0.0001$ \\
\hline Phonemic awareness & 88.6 & 10.8 & 97.6 & 8.7 & 0.002 & -8.9 & 0.002 & -8.7 & 0.002 & -8.5 & 0.004 \\
\hline Working memory & 84.4 & 10.7 & 95.6 & 11.4 & 0.0007 & -11.1 & 0.001 & -11.2 & 0.001 & -11.2 & 0.001 \\
\hline Cognitive fluency $^{\#}$ & 78.3 & 12.2 & 91.8 & 9.9 & 0.0001 & -13.5 & $<0.0001$ & -13.5 & $<0.0001$ & -14.8 & $<0.0001$ \\
\hline Executive processes $\#$ & 83.8 & 13.7 & 100.8 & 9.7 & $<0.0001$ & -17.0 & $<0.0001$ & -17.0 & $<0.0001$ & -17.1 & $<0.0001$ \\
\hline \multicolumn{12}{|l|}{ BRIEF-Adult } \\
\hline Inhibit & 49.3 & 7.9 & 47.1 & 7.0 & 0.319 & 2.3 & 0.319 & 2.4 & 0.305 & 2.0 & 0.385 \\
\hline Shift & 51.8 & 10.3 & 48.9 & 11.9 & 0.256 & 2.9 & 0.391 & 3.2 & 0.391 & 2.9 & 0.396 \\
\hline Emotional control & 51.5 & 8.6 & 47.7 & 10.2 & 0.067 & 3.9 & 0.180 & 4.0 & 0.162 & 3.6 & 0.225 \\
\hline Self-monitor & 49.5 & 8.6 & 46.4 & 9.8 & 0.212 & 3.1 & 0.270 & 3.2 & 0.251 & 3.1 & 0.291 \\
\hline Initiate & 50.5 & 10.9 & 49.2 & 9.4 & 0.795 & 1.3 & 0.677 & 1.5 & 0.626 & 1.5 & 0.642 \\
\hline Working memory & 53.7 & 11.5 & 49.4 & 8.9 & 0.218 & 4.3 & 0.178 & 4.6 & 0.112 & 4.4 & 0.180 \\
\hline Plan/Organize & 50.3 & 10.9 & 49.0 & 13.9 & 0.587 & 1.3 & 0.731 & 1.7 & 0.622 & 1.1 & 0.772 \\
\hline Task monitor & 51.5 & 11.5 & 48.7 & 8.7 & 0.571 & 2.8 & 0.372 & 3.2 & 0.240 & 2.4 & 0.452 \\
\hline Organization of materials & 49.8 & 8.2 & 50.3 & 8.7 & 0.870 & -0.4 & 0.870 & -0.2 & 0.929 & -0.7 & 0.779 \\
\hline Behavior regulation index & 50.8 & 8.8 & 47.6 & 10.5 & 0.266 & 3.3 & 0.266 & 3.5 & 0.214 & 3.3 & 0.278 \\
\hline Metacognitive index & 51.1 & 10.8 & 49.2 & 9.8 & 0.595 & 1.9 & 0.549 & 2.2 & 0.441 & 1.7 & 0.589 \\
\hline Global executive composite & 51.1 & 10.0 & 48.3 & 10.1 & 0.272 & 2.8 & 0.356 & 3.1 & 0.264 & 2.7 & 0.389 \\
\hline
\end{tabular}

${ }^{*} p$-values from the T-test or Wilcoxon rank-sum (Mann-Whitney) test; ${ }^{* *}$ Adjusted by age and gender; ${ }^{* * *}$ Adjusted by education. LRM Linear Regression Models. \#Neurocognitive measures are significant under the Bonferroni-Holmes corrections for all the statistical tests simultaneously

$N=17)$. The two groups did not differ on age or gender $(p>0.05)$, respectively (data not shown). Findings revealed that the two FAP groups were not significantly different on IQ $(p=0.709)$. However, FAP cases with mutations located within the classic mutation cluster had marginally lower performance on WoodcockMuñoz summary scores of Cognitive Efficiency $(p=$ $0.076)$ and Processing Speed, $(p=0.056)$, and on BRIEFAdult scales of Shift $(p=0.058)$ and Initiate $(p=0.081)$ compared to FAP cases with mutations in the attenuated FAP region (Table 3).

\section{Neurological examination}

A full neurologic examination was performed in all 26 cases and in 24 controls. No consistent pattern of abnormalities was observed in the cases or control subjects. Four cases showed findings consistent with a mild distal sensory neuropathy, in three of the cases this was related to prior chemotherapy for colon cancer.

\section{Discussion}

The findings of this study provide a proof-of-concept for an important role of the APC protein in neurocognitive function. Moreover, this investigation is the first to systematically evaluate neurocognition in the FAP population using a carefully matched case-control design, and evaluating important potential confounders such as anxiety, depression, and level of education. Our findings reflected significantly lower performance on IQ and in a variety of neurocognitive functions, with effect sizes being within the large range. Furthermore, for many of the specific neurocognitive functions, individuals with FAP performed in the bottom quartile, suggesting possible difficulties in these areas. Interestingly, there were no group differences noted on the adult selfratings (BRIEF questionnaire) of executive functions, perhaps secondary to self-perceptions not recognizing the subtle differences that might be present when compared to their peers. 
Table 3 Comparisons of FAP Severity Groups on Neurocognitive Functions

\begin{tabular}{|c|c|c|c|c|c|c|c|c|c|c|c|}
\hline \multirow[t]{2}{*}{ Measure } & \multicolumn{2}{|c|}{$\begin{array}{l}\text { Attenuated } \\
\text { FAP Group } \\
(n=9)\end{array}$} & \multicolumn{2}{|c|}{$\begin{array}{l}\text { Classic FAP } \\
\text { Group } \\
(n=17)\end{array}$} & \multirow[t]{2}{*}{$p$-value* } & \multirow[t]{2}{*}{$\begin{array}{l}\text { Simple LRM } \\
\text { (coefficients) }\end{array}$} & \multirow[t]{2}{*}{$p$-value } & \multirow[t]{2}{*}{$\begin{array}{l}\text { Adjusted multivariate } \\
\text { LRM }^{* *} \text { (coefficients) }\end{array}$} & \multirow[t]{2}{*}{$p$-value } & \multirow[t]{2}{*}{$\begin{array}{l}\text { Adjusted multivariate } \\
\text { LRM }^{* * *} \text { (coefficients) }\end{array}$} & \multirow[t]{2}{*}{$p$-value } \\
\hline & Mean & SD & Mean & SD & & & & & & & \\
\hline TONI-4 IQ & 91.2 & 4.5 & 90.2 & 6.3 & 0.662 & -1.0 & 0.662 & -1.0 & 0.670 & -0.9 & 0.709 \\
\hline \multicolumn{12}{|l|}{ Batería III clusters } \\
\hline Verbal ability & 89.7 & 5.5 & 87.4 & 8.7 & 0.479 & -2.3 & 0.479 & -2.3 & 0.504 & -2.0 & 0.566 \\
\hline Thinking ability & 81.8 & 10.0 & 79.9 & 10.9 & 0.669 & -1.9 & 0.669 & -2.0 & 0.671 & -1.8 & 0.704 \\
\hline Cognitive efficiency & 87.2 & 6.4 & 77.8 & 13.0 & 0.054 & -9.4 & 0.054 & -9.4 & 0.064 & -9.2 & 0.076 \\
\hline Long-term memory & 65.0 & 16.2 & 67.7 & 13.6 & 0.655 & 2.7 & 0.655 & 2.4 & 0.677 & 2.6 & 0.666 \\
\hline Processing speed & 92.9 & 7.9 & 81.0 & 16.0 & 0.048 & -11.9 & 0.048 & -12.1 & 0.045 & -11.4 & 0.056 \\
\hline Phonemic awareness & 91.1 & 11.1 & 87.3 & 10.7 & 0.400 & -3.8 & 0.400 & -3.8 & 0.419 & -4.2 & 0.379 \\
\hline Working memory & 88.6 & 6.6 & 82.2 & 11.9 & 0.154 & -6.3 & 0.154 & -6.2 & 0.168 & -6.1 & 0.189 \\
\hline Cognitive fluency & 82.4 & 11.0 & 76.1 & 12.5 & 0.210 & -6.4 & 0.210 & -6.5 & 0.164 & -6.2 & 0.193 \\
\hline Executive processes & 84.8 & 10.8 & 83.2 & 15.3 & 0.791 & -1.5 & 0.791 & -1.6 & 0.781 & -1.0 & 0.862 \\
\hline \multicolumn{12}{|l|}{ BRIEF-Adult } \\
\hline Inhibit & 50.4 & 5.9 & 48.8 & 8.8 & 0.657 & -1.6 & 0.657 & -1.3 & 0.712 & -0.5 & 0.886 \\
\hline Shift & 57.1 & 8.1 & 49.1 & 10.4 & 0.052 & -8.1 & 0.068 & -7.6 & 0.055 & -7.9 & 0.058 \\
\hline Emotional control & 52.5 & 6.1 & 51.0 & 9.8 & 0.519 & -1.5 & 0.696 & -1.2 & 0.742 & -1.3 & 0.726 \\
\hline Self-monitor & 52.4 & 9.3 & 48.9 & 8.1 & 0.229 & -4.4 & 0.249 & -4.0 & 0.253 & -5.2 & 0.134 \\
\hline Initiate & 55.8 & 12.2 & 47.9 & 9.5 & 0.070 & -7.9 & 0.095 & -7.4 & 0.082 & -7.9 & 0.081 \\
\hline Working memory & 52.9 & 12.6 & 54.1 & 11.4 & 0.735 & 1.2 & 0.818 & 1.8 & 0.663 & 1.3 & 0.760 \\
\hline Plan/Organize & 54.3 & 12.3 & 48.3 & 9.9 & 0.176 & -5.9 & 0.214 & -5.3 & 0.158 & -5.5 & 0.162 \\
\hline Task monitor & 54.8 & 10.9 & 49.9 & 11.8 & 0.310 & -4.8 & 0.345 & -4.1 & 0.287 & -3.6 & 0.369 \\
\hline $\begin{array}{l}\text { Organization of } \\
\text { materials }\end{array}$ & 50.8 & 8.6 & 49.4 & 8.2 & 0.706 & -1.4 & 0.706 & -1.1 & 0.744 & -0.5 & 0.882 \\
\hline $\begin{array}{l}\text { Behavior regulation } \\
\text { index }\end{array}$ & 53.6 & 6.7 & 49.4 & 9.6 & 0.281 & -4.2 & 0.281 & -3.7 & 0.270 & -3.8 & 0.283 \\
\hline Metacognitive index & 53.9 & 11.5 & 49.7 & 10.5 & 0.443 & -4.2 & 0.380 & -3.6 & 0.344 & -3.6 & 0.361 \\
\hline $\begin{array}{l}\text { Global executive } \\
\text { composite }\end{array}$ & 54.1 & 9.2 & 49.6 & 10.2 & 0.297 & -4.6 & 0.300 & -4.0 & 0.253 & -4.0 & 0.276 \\
\hline
\end{tabular}

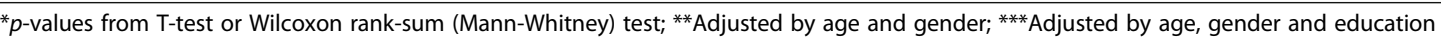

Original observations describing intellectual disabilities among individuals with FAP were limited to case reports $[4,5,7]$. Patients with FAP were shown to perform lower on test of intellectual capacity, particularly on verbal tasks, when compared to patients with ulcerative colitis [14]. In addition, a conference presentation by O'Malley et al. [13] directly examined the cognitive functioning of individuals with FAP by conducting a brief intelligence test with 44 adult subjects from 42 families. They found that the group performed in the average IQ range, with $27 \%$ of the sample performing in the bottom quartile. Verbal abilities were significantly lower than average, although not impaired (Verbal IQ $=95.5 \pm 12$ ), with the majority of participants having their verbal abilities significantly lower than their nonverbal abilities $(p=0.020)$. Our nonverval abilities were similar in the level to that obtained by O'Malley et al. The authors hypothesize that the APC protein was critical for dependent pathways in the cochlea and could have a role in (verbal) cognition. In contrast, our investigation is the first to incorporate an age-, gender-, and education-matched control group with a complete battery of neurocognitive tests enabling interrogation of multiple domains and corresponding anatomical regions. Moreover, our scientific rationale differs from that of previous investigators as it relates to the central role of the APC protein in the development of the synaptic complex in the central nervous system [2, 3].

The APC protein has multiple domains and binding patterns, which indicates a multi-functional nature [15]. The classic colorectal adenomatous polyposis seen in patients with FAP results from the known negative regulation of APC protein in the Wnt transcription pathway [16]. The APC protein also carries out microtubule- 
organizing functions in neurons [17-19], and has a role in synapse assembly [20]. The APC protein is found in many cell types including neurons in the adult rodent brain [21], and high levels of expression of the APC mRNA are observed during brain development [22, 23]. Moreover, APC protein functions in localizing nicotinic acetylcholine receptors (nAChRs) at neuronal synapses in vivo [24] organizing a multi-molecular complex that stabilizes the local cytoskeleton and links the alpha3nAChRs subunit to APC at postsynaptic sites [2]. This complex of proteins is required for coordinating presynaptic and postsynaptic maturation in cholinoceptive neurons in vertebrate animals [24]. This complex is vital in processing information as nicotinic receptors have a key role in attention, learning, and memory and are highly concentrated in the cerebral cortex, hippocampus, thalamus and limbic system [25]. Thus, truncated or absence of the APC protein in the brain among patients with FAP may result in altered neurocognitive functions including attention deficits and learning impairments, and our findings provide preliminary support for these assertions. Given the pathophysiology inherent in these processes, we had hypothesized that patients with FAP would show lower processing speed and cognitive efficiency than controls and, in fact, this is what was uncovered. This was in addition to a significant lower performance than controls in a host of other neurocognitive domains.

In an elegant study using a conditional APC knockout mouse with deletion targeted predominantly to forebrain excitatory neurons (hippocampus and cortex), Mohn et al. reported impaired hippocampal-dependent spatial learning [8]. APC knock-out mice had double the latency to goal, committing three times as many errors, and took less efficient routes to the goal compared to wild-type mice [8]. In this in vivo model, APC loss lead to excessive B-catenin and Wht signal transduction in the forebrain as well as cognitive impairments and an autistic-like presentation [8]. Similarly, Koshimizu et al. had reported that the APC gene plays a role in locomotion and working memory performance. These investigators reported decreased locomotor activity and agedependent working memory deficits using a heterozygous APC knockout mice model [26]. Hence, our clinical observations of significantly lower performance on IQ and a variety of specific neurocognitive functions among patients with FAP as compared to controls may result from defective APC protein in the synaptic complex in the central nervous system.

Most mutations found in patients with FAP represent truncating mutations of the APC gene [1] and clinical presentations typically follow a genotype-phenotype pattern although there are known exceptions [27, 28]. For instance, severe colorectal polyposis (> 1000 adenomas) correlates with mutations between codons 1250 and 1464 [29], while desmoid tumors may be more prevalent in persons with mutations after codon 1444 [30, 31]. In our current study, we examined neurocognitive functions across two genetically defined subgroups including individuals with attenuated-FAP and those with classic FAP as defined by the location of their APC mutations. The location of the mutation in the APC gene correlates with the length and function of the APC protein, with less function seen among those with mutations in the classic FAP region. Our exploratory analysis suggests differences in several categories including cognitive efficiency and processing speed, and selected executive functions (set shifting, initiation) with higher performance among patients with attenuated-FAP compared to those with classic FAP.

Evidence for a potential etiologic role of APC protein in neurodevelopmental disorders arises from human studies examining the association of APC gene polymorphisms and autism spectrum disorders [32]. Neurodevelopmental disorders such as autism spectrum disorder, bipolar disorder and schizophrenia may result from dysregulation of Wnt signaling [33], which is also seen in patients with FAP. Furthermore, deletions of the APC gene and occurrence of adenomatous polyposis have been reported in patients originally referred for autism [34]. In our Polyposis Registry [1], we have several patients with either mutations and/or deletion of the APC gene who are also diagnosed with autism spectrum disorder. The APC gene has also been claimed to be associated with susceptibility to schizophrenia [10], providing an additional line of evidence for the important role that APC protein may have in the etiology of neurodevelopmental disorders. Our study provides proof-of-concept and preliminary clinical data of the ubiquitous deficit in neurocognitive functions associated with mutations in the APC gene in a genetically defined syndrome.

The pervasive nature of the observed cognitive dysfunction suggests that loss or dysfunction of the APC protein occurs across the cerebral cortex. Moreover, the observed neurocognitive dysfunction followed a genotype-phenotype correlation as occurs with other clinical manifestations in FAP patients. However, as FAP is a chronic debilitating disease that impacts individuals from early adolescence it may negatively affect cognition by altering educational milestones due to medical/surgical management of the condition. We thus reviewed and contrasted the effect on neurocognitive outcomes in two well characterized genetically-driven chronic illnesses, Cystic Fibrosis and Sickle Cell Anemia [35-37]. Results of these studies showed that children with Cystic Fibrosis had general intelligence levels that were comparable to the general population of the same age group [36]. Furthermore, a study on psychological assessment in 
adults with Cystic Fibrosis could not detect an increase in depressive or anxiety related symptoms in the affected adults [38]. In contrast, studies on the neurocognitive effects in children and adolescents with Sickle Cell Anemia reported learning difficulties [37], need for special education supports [37], lower visual-motor abilities [39], and decreased verbal short-term memory [35]. These neurocognitive effects were associated with the severity of the Sickle Cell Anemia, which suggest the mechanism for the neurocognitive deficits observed is reduced oxygen delivery rather than other confounding social determinants $[35,37]$. The mechanism by which APC mutations cause neurocognitive dysfunction results from the major role of the APC protein in the development of the pre-post synaptic complex $[2,3]$. Thus, the mechanisms by which the neurocognitive deficits present in both illnesses (FAP vs. Sickle Cell Anemia) differ in etiology. Our study serves as a proof-of-concept for the potential role of APC protein in neurocognition among patients with FAP; however, our study could not fully account for the possible confounding effect on cognition of having a chronic condition, such as school absenteeism, frequent medical visits, among others.

It is also important to explore how patients with FAP might react to the results obtained in this pilot study, by examining the attitudes, emotional impact and perceptions of these individuals regarding their cognitive abilities. While we are clearly cognizant of this being yet another potential worry for patients with FAP and their families, early recognition of potential risk for cognitive difficulties might lay the foundation for earlier intervention and, perhaps, lessening or preventing such difficulties over the life course for individuals with FAP. Studies on the effects of other chronic illnesses affecting children and young adults are needed to fully elucidate if the neurocognitive effects seen in patients with FAP are partly due to a defective/truncated APC protein and not by other confounders. Our proof-of-concept findings would suggest that this is a viable path for further scientific inquiry.

\section{Conclusion}

Our study in a genetically defined hereditary syndrome provides preliminary clinical data supporting an important role of the APC protein in neurocognitive function and of the pervasive neurocognitive dysfunctions that may be associated with mutations in the APC gene. Validation of our current observations in larger ethnically diverse cohorts would support cognitive screening for individuals with FAP to establish therapeutic interventions early in life as done for other neurodevelopmental disorders. Hence, studies examining the role of the APC protein among individuals with other neurodevelopmental conditions that manifest cognitive impairment, such as autism spectrum disorders and schizophrenia $[40,41]$ are warranted.

\section{Acknowledgements}

The authors will like to thank Dr. Julyann Perez Mayoral for assistance with editing of the manuscript and editorial assistance. We would also want to thank our patients who participated in the study, provided their time and energy to the completion of the study. Also, we will like to thank the imaging center personnel, including Dr. Antonio Algaze at the UPR Medical Sciences Campus Radiolology Department and the Practice Plan for their support in the conduction of the imaging studies.

\section{Authors' contributions}

MCC designed the study, evaluated patients for recruitment and prepared manuscript, ACS and BC administered cognitive tests to recruited subjects and aided in manuscript preparation. $\mathrm{JH}, \mathrm{MO}, \mathrm{AC}$ recruited subjects for the study. $\mathrm{AC}, \mathrm{CM}$, and CAL administered and/or analyzed the neurological exams for participants and contributed to the preparation of the manuscript. MSS worked on the statistical analysis for the study. FMG and SRH worked on study design, data analysis and manuscript preparation/interpretation. All authors read and approved the final manuscript.

\section{Funding}

The project supported by the Biostatistics, Epidemiology and Bioinformatics Core (BEBiC) of the UPR/MDACC Partnership for Excellence in Cancer Research (Award Grant Number\# CA096297/CA096300 from the National Cancer Institute of the National Institutes of Health); and by the Biomedical Bioinformatics Core of the Puerto Rico Clinical and Translational Research

Consortium (Award Number 2U54MD007587 from the National Institute on Minority Health and Health Disparities and National Institute of Allergy and Infectious Diseases) and NIH grant P50CA62924.

\section{Availability of data and materials}

In accordance with guidelines, unidentified data and materials supporting the results reported in the article will be available upon request. The dataset will be available to interpret, replicate and build upon the findings reported in this article.

\section{Ethics approval and consent to participate}

The research protocol was approved by the Institutional Review Board of the UPR Medical Sciences Campus (approval number A2210515).

\section{Consent for publication}

Not Applicable.

\section{Competing interests}

MCC is advisor of EXACT Sciences and BeiGene Pharmaceuticals. Content related to her advisory roles is not related to the topic of the manuscript.

\section{Author details}

${ }^{1}$ Department of Medicine, University of Puerto Rico School of Medicine, UPR Medical Sciences Campus, PO BOX 365067, San Juan 00936, Puerto Rico. ${ }^{2}$ Department of Biochemistry, University of Puerto Rico School of Medicine, San Juan, Puerto Rico. ${ }^{3}$ Department of Medicine, Neurology Section, University of Puerto Rico School of Medicine, San Juan, Puerto Rico. ${ }^{4}$ Division of Cancer Biology, University of Puerto Rico Comprehensive Cancer Center, San Juan, Puerto Rico. ${ }^{5}$ Division of Gastroenterology, School of Medicine, Johns Hopkins University, Baltimore, MD, USA. 'University of Massachusetts Medical School, Worcester, MA, USA. ${ }^{7}$ Department of Allied Health Sciences, School of Medicine, University of North Carolina-Chapel Hill, Chapel Hill, NC, USA.

Received: 4 December 2019 Accepted: 26 January 2020

Published online: 24 February 2020

\section{References}

1. Cruz-Correa M, Diaz-Algorri Y, Mendez V, et al. Clinical characterization and mutation spectrum in Hispanic families with adenomatous polyposis syndromes. Familial Cancer. 2013;12(3):555-62.

2. Rosenberg MM, Yang F, Giovanni M, Mohn JL, Temburni MK, Jacob MH Adenomatous polyposis coli plays a key role, in vivo, in coordinating assembly of the neuronal nicotinic postsynaptic complex. Mol Cell Neurosci. 2008;38(2):138-52. 
3. Onouchi T, Takamori N, Senda T. Colocalization of APC and PSD-95 in the nerve fiber as well as in the post-synapse of matured neurons. Med Mol Morphol. 2012;45(3):152-60.

4. Raedle J, Friedl W, Engels H, Koenig R, Trojan J, Zeuzem S. A de novo deletion of chromosome $5 q$ causing familial adenomatous polyposis, dysmorphic features, and mild mental retardation. Am J Gastroenterol. 2001; 96(10):3016-20.

5. Heald B, Moran R, Milas M, Burke C, Eng C. Familial adenomatous polyposis in a patient with unexplained mental retardation. Nat Clin Pract Neurol. 2007;3(12):694-700.

6. Finch $\mathrm{R}$, Moore $\mathrm{HG}$, Lindor $\mathrm{N}$, et al. Familial adenomatous polyposis and mental retardation caused by a de novo chromosomal deletion at 5q15q22: report of a case. Dis Colon Rectum. 2005:48(11):2148-52.

7. Azofra AS, Kidambi TD, Jeremy $R$, et al. Differences in neuropsychological and behavioral parameters and brain structure in patients with familial adenomatous polyposis: a sibling-paired study. Hered Cancer Clin Pract. 2016;14:20.

8. Mohn JL, Alexander J, Pirone A, et al. Adenomatous polyposis coli protein deletion leads to cognitive and autism-like disabilities. Mol Psychiatry. 2014; 19(10):1133-42.

9. Gonzalez L, Alvarez J, Weinstein E, Korenis P. Familial adenomatous polyposis in an adolescent with coexisting schizophrenia: treatment strategies and implications. Mol Genet Genomic Med. 2015;3(5):391-5.

10. Cui $\mathrm{DH}$, Jiang KD, Jiang SD, Xu YF, Yao H. The tumor suppressor adenomatous polyposis coli gene is associated with susceptibility to schizophrenia. Mol Psychiatry. 2005;10(7):669-77.

11. Yang Z, Ma X, Wang Y, et al. Association of APC and REEP5 gene polymorphisms with major depression disorder and treatment response to antidepressants in a Han Chinese population. Gen Hosp Psychiatry. 2012 34(5):571-7.

12. Rosenberg MM, Yang F, Mohn JL, Storer EK, Jacob MH. The postsynaptic adenomatous polyposis coli (APC) multiprotein complex is required for localizing neuroligin and neurexin to neuronal nicotinic synapses in vivo. $J$ Neurosci. 2010;30(33):11073-85.

13. O'Malley M, LaGuardia L, Naugle R, Gensur C, Hammel J, Church J, Burke C. Cognitive function in Familial Adenomatous Polyposis: anyone out there listening? Hered Cancer Clin Pract. 2010;8(Suppl 1):P15.

14. Levitt AJ, Rodin G, Cohen Z, Berk T. Coping styles, psychopathology and intellectual performance in patients with familial adenomatous polyposis. Gen Hosp Psychiatry. 1992;14(1):61-8.

15. Fearnhead NS, Britton MP, Bodmer WF. The ABC of APC. Hum Mol Genet. 2001;10(7):721-33.

16. Polakis P. The adenomatous polyposis coli (APC) tumor suppressor. Biochim Biophys Acta. 1997;1332(3):F127-47

17. Shi SH, Cheng T, Jan LY, Jan YN. APC and GSK-3beta are involved in mPar3 targeting to the nascent axon and establishment of neuronal polarity. Curr Biol. 2004;14(22):2025-32

18. Votin V, Nelson WJ, Barth Al. Neurite outgrowth involves adenomatous polyposis coli protein and beta-catenin. J Cell Sci. 2005;118(Pt 24):5699-708.

19. Lee S, Chen DY, Zaki MS, et al. Bi-allelic loss of human APC2, encoding adenomatous polyposis coli protein 2, leads to Lissencephaly, subcortical heterotopia, and global developmental delay. Am J Hum Genet. 2019; 105(4):844-53.

20. Shimomura A, Ohkuma M, lizuka-Kogo A, et al. Requirement of the tumour suppressor APC for the clustering of PSD-95 and AMPA receptors in hippocampal neurons. Eur J Neurosci. 2007;26(4):903-12.

21. Brakeman JS, Gu SH, Wang XB, Dolin G, Baraban JM. Neuronal localization of the adenomatous polyposis coli tumor suppressor protein. Neuroscience. 1999;91(2):661-72.

22. Bhat RV, Baraban JM, Johnson RC, Eipper BA, Mains RE. High levels of expression of the tumor suppressor gene APC during development of the rat central nervous system. J Neurosci. 1994;14(5 Pt 2):3059-71.

23. Dobashi Y, Bhattacharjee RN, Toyoshima K, Akiyama T. Upregulation of the APC gene product during neuronal differentiation of rat pheochromocytoma PC12 cells. Biochem Biophys Res Commun. 1996; 224(2):479-83

24. Rosenberg MM, Yang F, Mohn JL, Storer EK, Jacob MH. The postsynaptic adenomatous polyposis coli (APC) multiprotein complex is required for localizing neurligin and neurexin to neuronal nicotinic synapses in vivo. J Neurosci. 2010;30(33):11073-85.

25. Benarroch EE. Acetylcholine in the cerebral cortex: effects and clinical implications. Neurology. 2010;75(7):659-65.
26. Koshimizu H, Fukui Y, Takao K, et al. Adenomatous polyposis coli heterozygous knockout mice display hypoactivity and age-dependent working memory deficits. Front Behav Neurosci. 2011;5:85.

27. Goss KH, Groden J. Biology of the adenomatous polyposis coli tumor suppressor. J Clin Oncol. 2000;18(9):1967-79.

28. Spirio LN, Samowitz W, Robertson J, et al. Alleles of APC modulate the frequency and classes of mutations that lead to colonic polyps. Nat Genet. 1998;20:385-8.

29. Nagase H, Miyoshi Y, Horii A, et al. Correlation between the location of germ-line mutations in the APC gene and the number of colorectal polyps in familial adenomatous polyposis patients. Cancer Res. 1992;52:4055-7.

30. Caspari R, Olschwang S, Friedl W, et al. Familial adenomatous polyposis: desmoid tumors and lack of ophtalmic lesions (CHRPE) associated with APC mutations beyond codon 1444. Hum Mol Genet. 1995:4:337-40.

31. Giardello FM, Petersen GM, Piantadosi S, et al. APC gene mutations and extraintestinal phenotype of familial adenomatous polyposis. Gut. 1997;40: $521-5$.

32. Zhou XL, Giacobini M, Anderlid BM, et al. Association of adenomatous polyposis coli (APC) gene polymorphisms with autism spectrum disorder (ASD). Am J Med Genet B Neuropsychiatr Genet. 2007;144B(3):351-4.

33. Okerlund ND, Cheyette BN. Synaptic Wnt signaling-a contributor to major psychiatric disorders? J Neurodev Disord. 2011:3(2):162-74.

34. Barber JC, Ellis KH, Bowles LV, et al. Adenomatous polyposis coli and a cytogenetic deletion of chromosome 5 resulting from a maternal intrachromosomal insertion. J Med Genet. 1994;31(4):312-6.

35. Hijmans $C T$, Grootenhuis MA, Oosterlaan J, Heijboer H, Peters M, Fijnvandraat K. Neurocognitive deficits in children with sickle cell disease are associated with the severity of anemia. Pediatr Blood Cancer. 2011;57(2): 297-302.

36. Moser JJ, Veale PM, McAllister DL, Archer DP. A systematic review and quantitative analysis of neurocognitive outcomes in children with four chronic illnesses. Paediatr Anaesth. 2013;23(11):1084-96.

37. Nunes S, Argollo N, Mota M, Vieira C, Sena EP. Comprehensive neuropsychological evaluation of children and adolescents with sickle cell anemia: a hospital-based sample. Rev Bras Hematol Hemoter. 2017;39(1):32-9.

38. Strauss GD, Wellisch DK. Psychological assessment of adults with cystic fibrosis. Int J Psychiatry Med. 1980;10(3):265-72.

39. Puffer ES, Schatz JC, Roberts CW. Association between somatic growth trajectory and cognitive functioning in young children with sickle cell disease. J Health Psychol. 2016;21(8):1620-9.

40. Deidda G, Bozarth IF, Cancedda L. Modulation of GABAergic transmission in development and neurodevelopmental disorders: investigating physiology and pathology to gain therapeutic perspectives. Front Cell Neurosci. 2014;8:119.

41. Doherty JL, Owen MJ. Genomic insights into the overlap between psychiatric disorders: implications for research and clinical practice. Genome Med. 2014;6(4):29.

\section{Publisher's Note}

Springer Nature remains neutral with regard to jurisdictional claims in published maps and institutional affiliations.

Ready to submit your research? Choose BMC and benefit from:

- fast, convenient online submission

- thorough peer review by experienced researchers in your field

- rapid publication on acceptance

- support for research data, including large and complex data types

- gold Open Access which fosters wider collaboration and increased citations

- maximum visibility for your research: over $100 \mathrm{M}$ website views per year

At $\mathrm{BMC}$, research is always in progress.

Learn more biomedcentral.com/submission 